\title{
Evaluation of thermoplastic resin as a new pattern material for posts: dimensional accuracy and detail reproduction
}

\begin{abstract}
Traditionally, dark-cure (cold-cure) acrylic resin is used as pattern material for cast post and core. A new post system that incorporates a specially designed plastic support rod and a thermoplastic resin has been introduced to the market and is claimed to simplify the procedure for cast posts fabrication.

The aim of the present work was to evaluate the dimensional accuracy and detail reproduction of thermoplastic resin when used as pattern or impression material for posts, and the amount of solid residue after ignition when used as pattern material.

Materials used were thermoplastic resin (Trigger Feed, Glue Gun, China), polyether rubber base material (Permadyne, ESPE), and Duralay acrylic resin (Relience Dental Manufacturing Co). A machined cut circular stainless steel (st.st) mold similar to those described in ADA specification No. 19 and BS 4269 was constructed with two horizontal and three vertical sharp line grooves. The scribed horizontal lines were used to measure the dimensional changes. The scribed vertical lines provided a measure of surface detail reproduction. A ring of $5 \mathrm{~mm}$ thickness was machined cut that placed on the circular st.st. mold shoulder leaving $2 \mathrm{~mm}$ thickness for the impression material. Thirty impressions of st. st. die were made, ten from each material used in the study. Three readings were made for each impression disc to the nearest $0.001 \mathrm{~mm}$ using a travelling microscope (Unitron Bi5-3174) at $\times 10$ magnification. The percentage of dimensional change was calculated. Surface detail reproduction was evaluated, by inspecting each vertical line under a travelling microscope (Unitron Bi5-3174) at X10 magnification using low-angle illumination. The reproduction was considered acceptable if two of three of the vertical lines were reproduced continuously and well defined for the full length. Two grams of thermoplastic resin and two grams of cold cure resin were ignited separately in porcelain crucible at $700^{\circ} \mathrm{C}$. The nonvolatile residue left was weight using electronic balance.
\end{abstract}

\section{Introduction}

Severe destruction of coronal portion of the tooth with pulp involvement needs endodontic treatment followed by restoring the tooth to its normal function. Such restorations involved posts-core construction with cast full crowns. Custom-made posts and cores are more preferable and popular, than ready made one, for the restoration of endodontically treated teeth especially when flared or elliptical canals exist. Custom-made post can be cast from a direct pattern or indirect one. ${ }^{1-3}$

A direct technique utilizing autopolymerizing resin, ${ }^{1}$ light-curing resin $^{4}$ or hard dental inlay casting wax are recommended for single canals whereas an indirect procedure utilizing soft dental inlay casting wax is more appropriate for multiple canals. ${ }^{5}$ Post pattern is made directly in the canal with the use of a cold-cure resin and a brushbead technique. The canal is lightly lubricated, and a loose fitting plastic dowel is typically used to support the resin. ${ }^{1}$ Light-curing resin materials are available for the fabrication of patterns for cast metal post-cores. The materials are provided as high or low viscosity pastes or liquids and are based on a diurethane methacrylate oligomer with $40 \%$ to $55 \%$ resin filler. A pattern is fabricated by applying the resin in layers and curing in a light chamber or by using a handheld light-
Volume I Issue I - 2014

\author{
Nagy Abdul-Samee Abdul-Hameed \\ Dental Biomaterials, College of Oral and Dental Medicine, Misr \\ University for Science \& Technology, Egypt
}

Correspondence: Nagy Abdul-Samee Abdul-Hameed, Dental Biomaterials, College of Oral and Dental Medicine, Misr University for Science \& Technology, Al-Motamayez District, P.O. Box: 77, 6th of October City, Egypt, Email nagyabdlsamee@yahoo.com

Received: April 17, 20I4 | Published: May 07, 2014

Results of the study showed that there was no statistically significant difference in surface detail reproduction as well as dimensional stability during hardening between thermoplastic resin, cold-cure resin pattern material or polyether elastomeric impression material. There was no statistical significant difference in the percentages of solid residue left after burning out of thermoplastic resin or cold cure resin.

Clinical relevance: Thermoplastic resin is a cheap, low cost, easily manipulated, elastic material, and as accurate and dimensionally stable as the rigid cold cure resin pattern. Hence, it must replace the traditional post-core pattern materials or impression materials for post hole(s).

Keywords: thermoplastic resin, pattern materials, post, dimensional accuracy, detail reproduction

curing unit. ${ }^{4}$ Hard inlay pattern wax is also used for construction of direct pattern of cast post and core. ${ }^{6}$ Resin pattern has higher strength, higher resistance to flow and good dimensional stability than wax. ${ }^{4}$

Difficulties that can be encountered with the use of these materials include voids in the pattern, locking of the pattern into undercuts or collateral canals, and fracture of the resin or the wax during removal. Furthermore, the use of cold-cure resin is time-consuming to polymerize. A new post system (cast posts and plastic, Merritt EZ Cast Post Inc., Hendersonville, N.C.) that incorporates a specially designed plastic support rod and a thermoplastic resin has been introduced to the market and claimed to simplify the procedure for the fabrication of cast posts. ${ }^{7}$

The aim of the present work was to evaluate the dimensional accuracy and detail reproduction of thermoplastic resin when used as pattern or impression material for posts, and the amount of solid residue after ignition when used as pattern material.

\section{Materials and methods}

Materials used were thermoplastic resin (Trigger Feed, Glue Gun, China), polyether rubber base material (Permadyne, ESPE), and Duralay acrylic resin (Relience Dental Manufacturing Co). 


\section{Specimen preparation}

A machined cut circular stainless steel (st.st) mold (Figure 1) similar to those described in ADA specification No. $19^{8}$ and BS $4269^{9}$ was constructed with two horizontal and three vertical sharp line grooves. The horizontal lines were numbered $\mathrm{d}$ and d' and the distance d-d' is measured on the st.st. die (Figure 2a) and compared with that on the pattern (impression) discs (Figure $2 b$ ) to give an indication of dimensional changes. The vertical lines are numbered 1, 2 and 3 . They are ' $\mathrm{V}$ ' shaped in section and are $0.075,0.05$, and $0.02 \mathrm{~mm}$ wide respectively. The scribed vertical lines provided a measure of surface detail reproduction. A ring of $5 \mathrm{~mm}$ thickness was machined cut that placed on the circular st.st. mold shoulder leaving $2 \mathrm{~mm}$ thickness for the impression material.

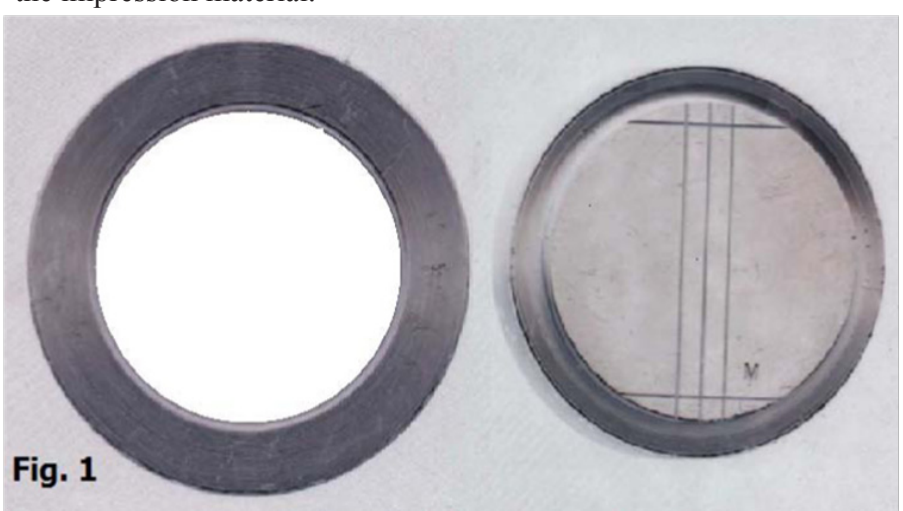

Figure I Stainless steel mold.

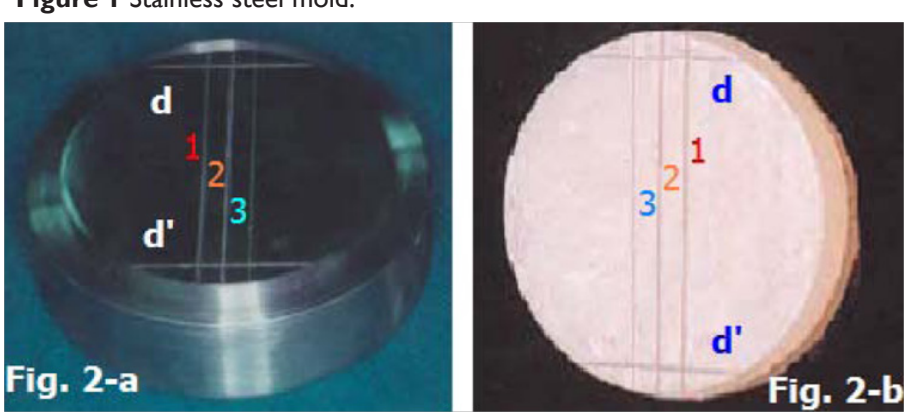

Figure 2 The horizontal lines were numbered $d$ and $d$, and the distance $d-d$ ' is measured on the st.st. die (Figure 2a) and compared with that on the pattern (impression) discs (Figure 2b).

Thirty impressions of st. st. die were made from each material used in the study. The stainless steel die was warmed to $37^{\circ} \mathrm{C}$, each time before loading with the materials under investigation, to simulate oral conditions. The rubber base and duralay impressions were made following manufacturer's directions. Thermoplastic resin impressions were made. Softening the resin using electrical gun (Figure 3) and care was taken to push the impression material ahead of the gun tip inside the st.st. mold. Pressure was exerted on the top of the mold using a flat metal piece of 500 grams weight that lined with polyethylene strip. The entire assembly is kept in water bath at $32 \pm 1^{\circ} \mathrm{C}$ in accordance with ADA specification No.19 for 10 minutes.

\section{valuation of dimensional accuracy}

Three readings were made for each impression disc to the nearest $0.001 \mathrm{~mm}$ using a travelling microscope (Unitron Bi5-3174) at $\times 10$ magnification. The percentage of dimensional change was calculated by the following equation:
Percentage of solid residue $=\frac{\text { Weight of material after ignition }}{\text { Weight of material before ignition }} X 100$

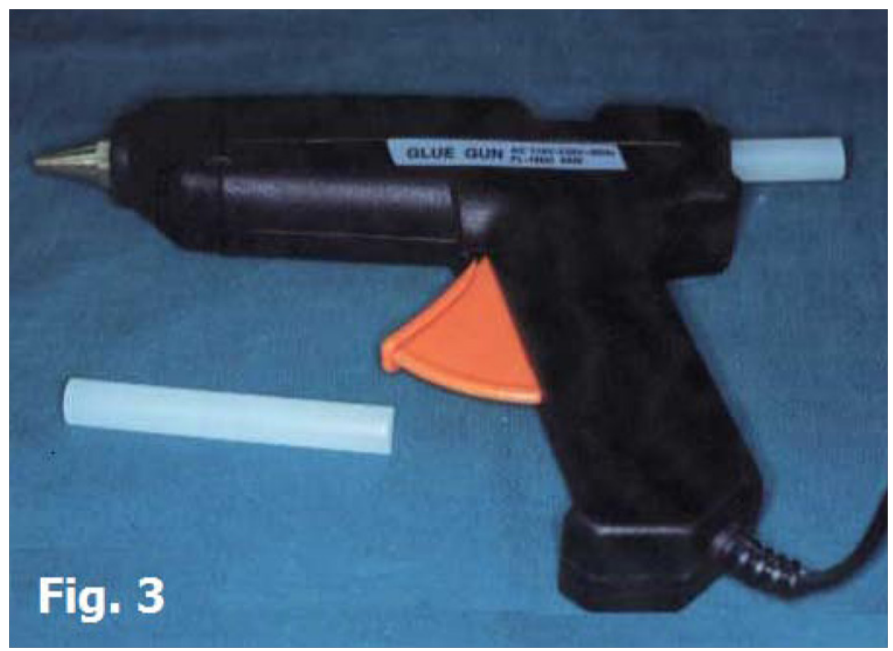

Figure 3 Electrical gun loaded with thermoplastic resin.

\section{valuation of surface detail reproduction}

Surface detail reproduction was evaluated one hour after removal of the impression from the water bath. Each vertical line (numbered 1,2 , and 3 ) was inspected under a travelling microscope (Unitron Bi53174 ) at X 10 magnification using low-angle illumination.

The reproduction was considered:

1. Acceptable if two of three of the vertical lines were reproduced continuously and well defined for the full length.

2. Unacceptable if any part of the line was indistinct, e.g., appeared melted or flattened, or the borders of the line were fuzzy or blurred. ${ }^{10}$

\section{Measurements of the amount of non-volatile residue}

Two grams of thermoplastic resin and two grams of cold cure resin were ignited separately in porcelain crucible at $700^{\circ} \mathrm{C}$. The nonvolatile residue left was weighed using Metler electric balance (sensitive to $0.0001 \mathrm{mg}$ ) according to the technique recommended by ADA Specification No 4 for inlay pattern waxes. ${ }^{11}$ The percentage of solid residue was calculated using the following formula:

\section{Percentage of solid residue $=\frac{\text { Weight of material after ignition }}{\text { Weight of material before ignition }} X 100$ \\ Statistical analysis}

The dimensional accuracy data were evaluated statistically using one way analysis of variance (ANOVA). Reliability of the dimensional accuracy for observers was taken against the standard stainless steel die.

The amount of solid residue data was collected and comparison of means was conducted by the use of the unpaired t-test. All tests were performed at a confidence level of $95 \%$. 


\section{Results}

\section{Dimensional accuracy}

There was no statistically significant difference $(P>0.05)$ in dimensional accuracy between the three types of materials used and the standard die or between any of the materials used (Table 1). Dimensional change values ranged from $-0.22 \%$ to $-0.26 \%$ for the materials used. All values were within the ADA standards of less than $0.5 \%$ shrinkage for the non-aqueous elastomeric dental impression materials.

\section{Surface detail reproduction}

All the impressions proved to have acceptable surface detail (Table
2). The lines were clearly reproduced with distinct edges along their entire length (Figure $4 \mathrm{a}$ for polyether elastomeric impression material, Figure $4 \mathrm{~b}$ for cold cure resin and Figure $4 \mathrm{c}$ for the thermoplastic resin).

\section{The amount of non-volatile residue}

The percentage of solid residue (Table 3 ) left after burning out of thermoplastic resin was $0.079 \pm 0.004$ and that of cold cure resin was $0.082 \pm 0.002$. There was no statistically significant difference between them in this respect $(P>0.05)$. Each one was within the limits of ANSA/ADA Specification No. 4 for dental inlay casting wax, which limits the non volatile (solid) residue be not more than $0.10 \%$ of the original weight of the specimen at an ignition temperature of $700^{\circ} \mathrm{C} .{ }^{12}$

Table I One-way analysis of variance (ANOVA) of the dimensional accuracy (linear dimensional change \%)

\begin{tabular}{|c|c|c|c|c|c|c|c|c|}
\hline \multicolumn{2}{|c|}{ Polyether } & \multicolumn{2}{|c|}{ Duralay } & \multicolumn{2}{|c|}{ Thermoplastic resin } & \multirow{2}{*}{ Calculated $F$ value } & \multirow{2}{*}{ Tabulated $F$ value } & \multirow{2}{*}{ Pvalue } \\
\hline $\mathbf{x}$ & SD & $\mathbf{x}$ & SD & $\mathbf{x}$ & SD & & & \\
\hline 0.22 & \pm 0.081 & 0.23 & \pm 0.095 & 0.26 & \pm 0.073 & 0.00064 & $3.354 I$ & $P>0.05(\mathrm{NS})$ \\
\hline
\end{tabular}

$X:$ Mean; SD: Standard Deviation; NS: Non Significant Difference $P>0.05$.

Table 2 Surface detail reproduction

\begin{tabular}{lccc}
\hline Result & Polyether & Duralay & Thermoplastic resin \\
\hline Acceptable & 10 & 10 & 10 \\
Unacceptable & 0 & 0 & 0 \\
\hline
\end{tabular}

Table 3 Unpaired t-test of the amount of nonvolatile residue (\%)

\begin{tabular}{|c|c|c|c|c|c|c|}
\hline \multicolumn{2}{|c|}{ Duralay } & \multicolumn{2}{|c|}{ Thermoplastic resin } & \multirow{2}{*}{ Calculated tvalue } & \multirow{2}{*}{ Tabulated tvalue } & \multirow{2}{*}{$P$ value } \\
\hline$x$ & SD & $\mathbf{x}$ & SD & & & \\
\hline 0.082 & \pm 0.002 & 0.079 & \pm 0.004 & 0.0386 & 2.101 & $P>0.05$ (NS) \\
\hline
\end{tabular}

NS: Non significant difference $\mathrm{P}>0.05$.

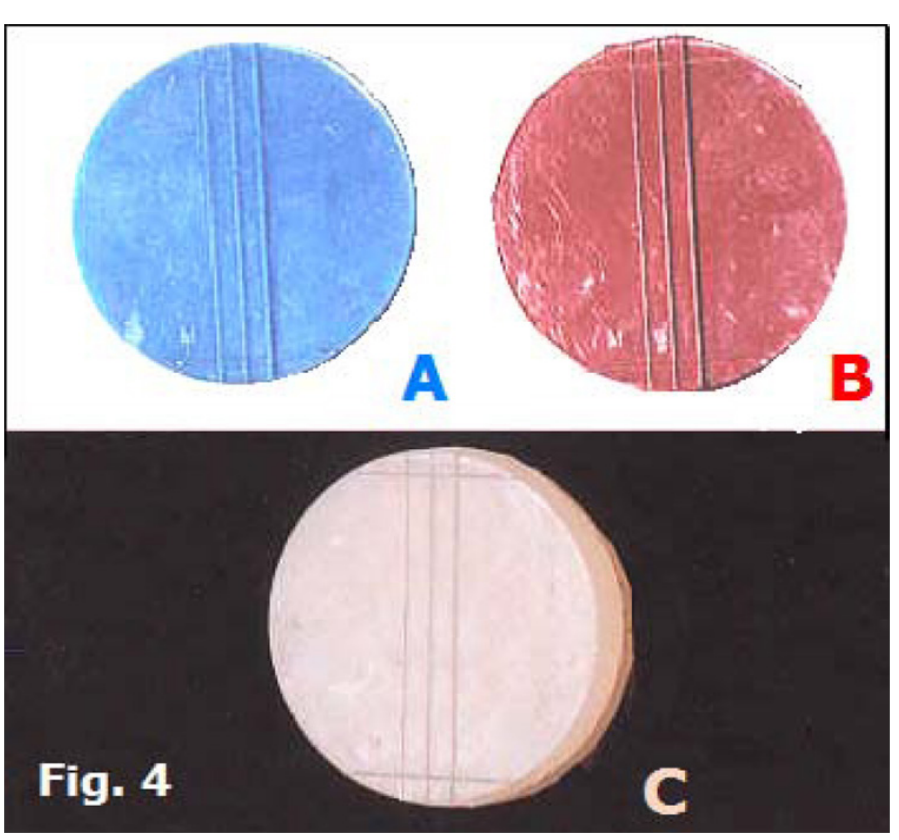

Figure 4 Surface details. A: For polyether elastomeric impression material; B: For cold cure resin; C: for the thermoplastic resin.

\section{Discussion}

Advantages of using thermoplastic resins as a direct pattern material in manufacturing of cast post and core are: low cost, the amount of time needed for its cooling and solidifying is 1 minute which is much less than the time needed for polymerization of coldcure resin or incremental building of the inlay pattern wax, good flow in its molten state which leaves the surface of the post pattern free from voids that may affect the accuracy of the investing procedures, and enough elasticity that allows its withdrawal from undercut. Another merit for the thermoplastic resin is that it could be used as an impression for the post hole preparation for the indirect technique. ${ }^{7}$ This paid our attention to evaluate its dimensional accuracy, detail reproduction and the amount of solid residue left after ignition.

In this study the test material was compared with cold cure resin (Duralay) because it is the most commonly used material for direct pattern construction and with polyether rubber base impression material because it is one of the most dimensionally stable impression material.

Although thermoplastic resin produced the largest dimensional changes $(0.26 \pm 0.073)$ but no statistical significant difference $(\mathrm{P}>0.05)$ was found between it and other materials tested (Polyether $0.22 \pm 0.081$ \& Duralay $0.23 \pm 0.095)$. The contraction of cold cure resin and polyether rubber base during their setting could be attributed to the 
cross-linking and rearrangement of bonds within and between polymer chains. ${ }^{8}$ The contraction of thermoplastic resin during its hardening is explained on the basis of coefficient of thermal expansion. ${ }^{12}$ Furthermore, the present work showed that the dimensional changes of the investigated materials were within the ADA specifications No. 19 for the non-aqueous elastomeric impression material. ${ }^{8}$

Regarding detail reproduction, all materials used in this study were acceptable because all the three vertical lines were reproduced continuously and well defined for the full length. This may be attributed to the high flow, of all materials investigated, at the time of mold packing. There was no statistically significant difference of the solid residue left after burning out of thermoplastic resin and cold cure resin $(\mathrm{P}>0.05)$. Moreover, these solid residues were within the limits of ANSA/ADA Specification No. 4 (ISO 1561) for dental inlay casting wax. This could be attributed to the fact that both of them are formed of organic materials. The coloring materials in the cold cure resin that used as pattern material (e.g. Duralay), are also organic one.

\section{Conclusion}

Within the limits of this work, the following conclusions were derived from the results:

1. Thermoplastic resin is as dimensionally stable as cold-cure resin pattern material or polyether elastomeric imression material.

2. There was no statistically significant difference in surface detail reproduction between thermoplastic resin, cold-cure resin pattern material or polyether elastomeric impression material.

3. There was no statistically significant difference in the percentages of solid residue left after burning out of thermoplastic resin or cold cure resin.

\section{Acknowledgments}

None.

\section{Conflict of interest}

The author declares that there is no conflict of interest.

\section{References}

1. Rosenstiel SF, Land MF, Fujimoto J. Contemporary fixed prosthodontics. $2^{\text {nd }}$ ed. Mosby-Year Book, St Louis: USA;1995:238-262.

2. Milot P, Stein RS. Root fracture in endodontically treated teeth related to post selection and crown design. J prosthet Dent. 1992;68(3):428-435.

3. Trabert KC, Conney JP. The endodontically treated tooth. Restorative concepts and techniques. Dent Clin North Am. 1984;28(4):923-951.

4. O'Brien WJ. Dental materials and their selection. $2^{\text {nd }}$ ed. Quintessence Publishing, Illinois: USA.

5. Council on Dental Materials, Instruments, and Equipments. Revised ANSA/ADA Specification No. 4 (ISO 1561) for inlay wax. $J$ Am Dent Assoc. 1984;108:88.

6. Ingle JI, Bakland LK. Endodontics: Restoration of the endodontically treated teeth. $5^{\text {th }}$ ed. BC Decker Inc, Hamilton, London; 2002.

7. Rosenstiel SF, Land MF, Holloway JA. Custom-cast post fabrication with thermoplastic material. J Prosthet Dent. 1997;77(2):209-211.

8. American Dental Association. Revised American Dental Association Specification No.19 for non-aqueous elastomeric dental impression materials. J Am Dent Assoc. 1997;94(4):733-741.

9. BSI Group. Dental elastic impression material. Specification for elastomeric impression materials. British Standards Institution, London, BS 4269 Part 1. 1987.

10. O'Mahony A, Spencer P, Williams K, et al. Effect of 3 medicaments on the dimensional accuracy and surface detail reproduction of polyvinyl siloxane impressions. Quintessence Int. 2000;31(3):201-206.

11. Anusavice K. Phillips' Science of dental materials. $11^{\text {th }}$ ed. W.B. Saunders Co; 2003.

12. Craig RG, Powers JM. Restorative Dental Materials. $11^{\text {th }}$ ed. Mosby; 2002. 